\title{
Outcomes of Survival Analysis of Patients Who Operated For NSCLC According to Subgroups of T3N0 Tumors
}

Küçük Hücreli Dışı Akciğer Kanseri Tanısıyla Opere Edilen Hastalarda T3N0 Tümörlerin Subgrubuna Göre Sağkalım Analizi Sonuçları

\author{
Muhammet Sayan, (D) Merve Şatır Türk, iD Aynur Baş, iD Ali Çelik, ID İsmail Cüneyt Kurul, \\ Olgun Kadir Arıbaş, iD Abdullah İrfan Taştepe \\ Gazi Üniversitesi, Göğüs Cerrahisi Anabilim Dalı, Ankara,
}

\begin{abstract}
Aim: According to the 8th TNM lung cancer staging, T3 tumors are a heterogeneous group and the tumor accepted as T3 due to tumor diameter (5 to $7 \mathrm{~cm}$ ), invasion the adjacent tissue (thoracic wall, pericardium, phrenic nerve, parietal pleura) and satellite malignant nodule in the same lobe. In our study, the survival difference between T3 tumor subgroups in the same stage (stage IIB) was investigated.

Material and methods: Following the approval of the local ethics committee, patients who were operated with a diagnosis of NSCLC between January 2010 and December 2018 and whose pathological staging was reported as pT3NOMO were included. The data of patients were analyzed according to age, gender, pT3 subgroup, histopathological type, tumor diameter, visceral pleural invasion.

Results: A total of 83 patients fulfilled the inclusion criteria were included in the study. 72 (\%86.8) of the patients were male and 11 (13.2 \%) were female. The median age was 62 (36-81) and mean tumor diameter was $4.9 \mathrm{~cm}$ (SD:2.1). The surgical resections were as follows; lobectomy was performed in 45 patients (54.2\%), bilobectomy in 9 patients (12.1\%), pneumonectomy in 14 patients (16.9\%), segmentectomy in 3 patients (3.6\%) and lung resection with chest wall resection in 11 patients (13.2 \%). The pT3 subgroups were as follows, 38 (45.2\%) diameter subgroups, 11 (13.7\%) invasion subgroups, 7 (8.5\%) parietal pleural invasion subgroups (without chest wall invasion), 10 (12.1\%) satellite nodule subgroups and 17 (20.5\%) multi-mix subgroups. The worst median survival was 22 months (7.1-37.0) in the invasion subgroup, while the best survival was in the diameter subgroup (median survival was 68.8 months, range 43.9-89.6 months). The difference was statistically significant $(p=0.001)$. Survival in the pneumonectomy group was significantly worse $(p=0.005)$.

Conclusion: In non-small cell lung cancer, tumors of the same pathological stage may show a significant survival difference between subgroups. If these results are supported by more centered and studies including more patients, there may be additional factors in lung cancer staging.

ÖZET

Amaç: Akciğer kanserlerinin 8.TNM evrelemesine göre T3 tümörler heterojen bir grubu içermekte olup çap, aynı lobta satellit nodül ve invazyon (toraks duvarı, perikard, frenik sinir, parietal plevra) sebebiyle t3 kabul edilebilmektedir. Çalışmamızda aynı evredeki (evre IIB) T3 tümör subgrupları arasında sağkalım farkı araştırldd.

Gereç ve Yöntemler: Çalışmamıza lokal etik onayını takiben Ocak2010-Aralık 2018 arasında Küçük Hücreli Dışı Akciğer Kanseri (KHDAK) tanıslyla opere edilen ve patolojik evrelemesi T3NO olarak raporlanan hastalar dahil edildi. Hastalar yaş, cinsiyet, T3 alt grubu, histopatolojik tip, tümör çapı, parietal plevra invazyonuna göre analiz edildi.

Bulgular: Çalışmaya kriterleri taşlyan 83 hasta dahil edildi. Hastaları 72' si (\%86.8) erkek, 11 'i (\%13.2) kadındl. Median yaş 62 (36-81) ortalama tümör çapı $4.9 \mathrm{~cm}$ (SS:2.1) idi. Uygulanan operasyona göre 45 hastaya (\%54.2) lobektomi, 9 hastaya (\%12.1) bilobektomi, 14 hastaya (\%16.9) pnömonektomi, 11 hastaya (\%13.2) akciğer rezeksiyonu + toraks duvar rezeksiyonu 3 hastaya (\%3.6) segmentektomi operasyonu yapıldl. T3 alt grubları şu şekilde idi; 38 hastada (\%45.7) tümör çapı, 11 hastada (\%13.2) çevre doku invazyonu, 7 hastada (\%8.5) parietal plevra invazyonu (toraks duvarl invazyonu olmadan) ve 10 hastada (\%12.1) ayn lobta satellit nodül ve 17 hastada (\%20.5) çoklu- miks sebep mevcuttu. En kötü median sağkalım çevre invazyon alt grubunda 22 ay (7.1-37.0) iken, en iyi sağkalım çap subgrubunda idi. Fark istatistiksel olarak anlaml idi $(p=0.001)$. Pnömonektomi grubunda sağkalım anlamlı olarak kötüydü $(p=0.005)$.

Sonuç: KHDAK' de aynı patolojik evredeki tümörlerde alt gruplar arasında anlamlı sağkalım farkı görülebilmektedir. Sonuçlar daha çok merkezli ve daha çok hasta sayısı içeren çalıșmalarla desteklenirse kanser evrelemesinde ilave faktörler gündeme gelebilir.
\end{abstract}

Key Words:

Lung cancer,

Prognosis,

pT3,

$8^{\text {th }}$ TNM.

Anahtar Kelimeler:

Akciğer kanseri,

Prognoz,

pT3,

8.TNM.

Cite this article as: Sayan M, Türk MŞ, Baş A, Çelik A, Kurul İC, Arıbaş OK, Taştepe Aİ. Outcomes of Survival Analysis of Patients Who Operated For NSCLC According to Subgroups of T3N0 Tumors. Phnx Med J. 2020;2(2):85-89. 


\section{Sayan et al}

\section{GíRIŞ}

Akciğer kanseri dünya genelinde kanser ilişkili ölümlerin başında gelmektedir ve çoğunluğu küçük hücreli dış1 akciğer kanseridir (1). Akciğer kanserinde en önemli prognostik faktörün tümörün evresi olduğu bildirilmiştir. Sekizinci TNM evrelemesine göre T3 tümörler tümörün çap1 $(>5-7 \mathrm{~cm})$, aynı lobta birden fazla aynı histopatolojideki tümör nodülü varlığı, parietal plevra invazyonu ve çevre doku invazyonu (toraks duvarı, perikard, frenik sinir) içermektedir (2). Çalışmamızda aynı T faktörüne sahip hastalardaki bu alt gruplar arasındaki sağkalım farkı araştırıldı.

\section{GEREÇ VE YÖNTEM}

Hasta seçimi:

Lokal etik kurul onayını (Gazi Üniversitesi Etik Kurulu-2009/0.06, sayı: 91610558-604.01.02) takiben kliniğimizde küçük hücreli dışı akciğer kanseri
(KHDAK) tanısıyla opere edilen ve patolojik evrelemede T3N0M0 grubunda yer alan hastaların verileri geriye dönük olarak incelendi. Homojen bir hasta grubu oluşturmak için neoadjuvan tedavi alanlar, nöroendokrin tümör histopatolojisinde olanlar, lenf nodu diseksiyonu yapılmayan hastalar ve anatomik rezeksiyon uygulanmayan hastalar çalışmaya alınmadı. Çalışmaya erişkin hasta popülasyonu dahil edildi ve çalışmamızdaki yaş dağılımı 36-81 idi. Hastalar yaş, cinsiyet, tümör histopatolojisi, uygulanan cerrahi, T3 alt grubuna göre analiz edildi.

İstatistiksel Analiz:

Tüm analizler SPSS (version 20.0, IBM, USA) programı ile yapıldı. Genel sağkalım belirlenmesinde çalışma süresi içinde kaybedilen hastalarda ölüm tarihi, hayatta olan hastalar için çalışmanın yapıldığı tarih baz alınd. Genel sağkalım ve median sağkalım için Kaplan-Meier yöntemi kullanıldı, gruplar arasındaki

Tablo: Hastaların demografik, klinik, histopatolojik, cerrahi tip ve T3N0M0 subgrubuna göre sağkalım karşılaştırmaları

\begin{tabular}{|c|c|c|c|c|c|}
\hline & & $\mathbf{n}$ & $\%$ & $\begin{array}{c}\text { Median Sağkalım } \\
\text { (Dağılım) }\end{array}$ & p değeri \\
\hline Yaş & Median:62, (Dağılım: 36-81) & & & & \\
\hline Tümör çapı & Ortalama: 4.9 (SS:2.1) & & & & \\
\hline \multicolumn{6}{|l|}{ Cinsiyet } \\
\hline & Kadın & 11 & 13.2 & 82.2 ay (58.0-106.1) & \multirow[t]{2}{*}{0.09} \\
\hline & Erkek & 72 & 86.8 & 58.6 ay (46.6-70.5) & \\
\hline \multicolumn{6}{|l|}{ Histopatoloji } \\
\hline & Adenokarsinom & 41 & 49.4 & 69.0 ay (53.5-84.6) & \multirow{4}{*}{$\mathrm{p}>0,05$} \\
\hline & SCC & 30 & 36.2 & 48.6 ay (32.9-63.9) & \\
\hline & ASC & 3 & 3.6 & 61.6 ay (24.3-99.0) & \\
\hline & Diğer $^{1}$ & 9 & 10.8 & 51.3 ay (32.6-69.9) & \\
\hline \multicolumn{6}{|l|}{ Cerrahi Tipi } \\
\hline & Lobektomi & 45 & 54.2 & 80.0 ay (61.8-98.2) & \multirow{5}{*}{$0.005^{2}$} \\
\hline & Bilobektomi & 10 & 12.1 & 70.5 ay (55.6-85.4) & \\
\hline & Pnömonektomi & 14 & 16.9 & 20.7 ay (10.0-31.4) & \\
\hline & $\begin{array}{l}\text { Akciğer Rezeksiyonu + } \\
\text { Göğüs Duvarı Rezeksiyonu }\end{array}$ & 11 & 13.2 & 38.2 ay (20.8-55.7) & \\
\hline & Segmentektomi & 3 & 3.6 & 62.0 ay (60.9-62.9) & \\
\hline \multicolumn{6}{|c|}{ T3N0M0 Altgrubu } \\
\hline & Çap & 38 & 45.7 & 70.1 ay (57.1-83.2) & \multirow{4}{*}{$0.001^{3}$} \\
\hline & Çevre İnvazyonu & 11 & 13.2 & 22.0 ay (7.1-37.0) & \\
\hline & Satellit Nodül & 10 & 12.1 & 68.8 ay $(43.9-89.6)$ & \\
\hline & PPİ & 7 & 8.5 & 58.7 ay (23.9-93.5) & \\
\hline & Miks & 17 & 20.5 & 38.5 ay $(18.9-58.1)$ & $0.04^{4}$ \\
\hline \multicolumn{6}{|c|}{$\begin{array}{l}\text { Kisaltmalar: ASC: Adenoskuamoz Karsinom, PPİ: Parietal Plevra İnvazyonu, SCC: Skuamoz Hücreli Karsinom, Miks: Çoklu sebep } \\
\text { (çap + plevra invazyonu, Satellit nodül + Çap vs) }\end{array}$} \\
\hline \multicolumn{6}{|c|}{ Acıklamalar: } \\
\hline \multicolumn{6}{|c|}{ 1:Diğer Histopatoji: Pleomorfik Karsinom, Mukoepidermoid Karsinom, Büyük Hücreli Karsinom } \\
\hline \multicolumn{6}{|c|}{ 2:Pnömonektomi ile diğer cerrahi yapılan grup karşılaştırıldığında sağkalım farkı istatistiksel olarak anlamlı. } \\
\hline \multicolumn{6}{|c|}{ 3:Çevre İnvazyon alt grubunun sağkalımı, Çap-Satellit nodül ve PPİ alt gruplarının sağkalımına göre anlamlı olarak kötü bulundu. } \\
\hline
\end{tabular}


Phnx Med J. July, 2020. Volume 2 No 2

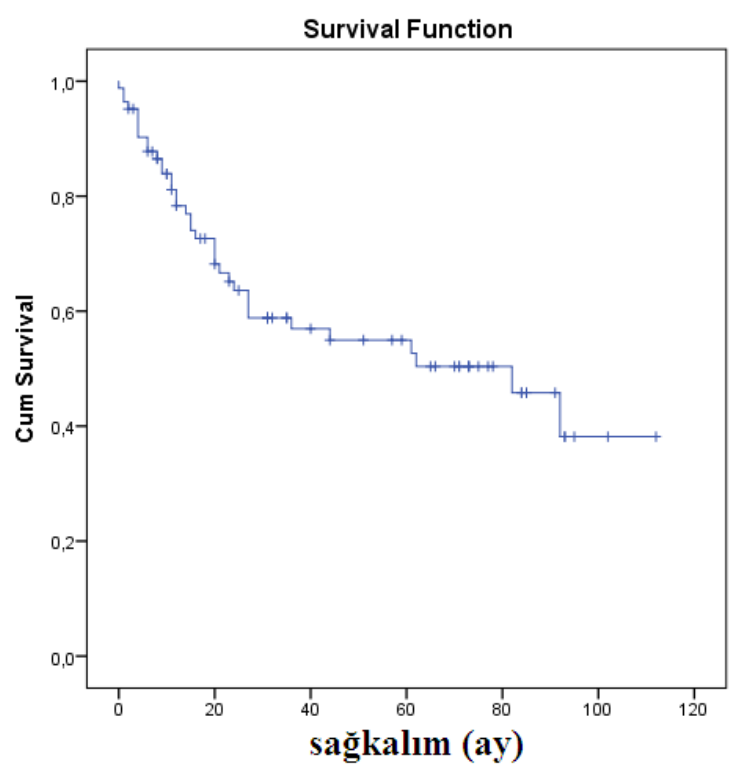

Resim 1: Hastalara ait genel sağkalım eğrisi

sağkalım fark1 için Log-Rank testi kullanıldı. Cok değiş̧kenli analizler Cox-Regresyon yöntemiyle yapıldı. Analizler \%95 güven aralığında yapıldı. Çift yönlü $\mathrm{p}$ değeri hesaplandı. $\mathrm{P}$ değerinin 0.05 ten küçük olması istatistiksel olarak anlamlı kabul edildi.

\section{BULGULAR}

Çalışmaya kriterleri karşılayan 83 hasta alındı. Hastaya ait klinikopatolojik ve demografik veriler tabloda belirtilmiștir. Median yaş 62 (dağılım:36-81), ortalama tümör çapı; 4.9 (SS:2.1) cm idi. 11 hasta (13.3\%) kadın, 72 hasta (\% 86.7) erkekti. Histopatolojik olarak 41 hastada adenokarsinom, 30 hastada skuamoz hücreli karsinom, 3 hasta adenoskuamoz karsinom, 9 hastada diğer (Pleomorfik Karsinom, Mukoepidermoid Karsinom, Büyük Hücreli Karsinom ) histopatoloji saptandı. Uygulanan cerrahiler şu şekilde idi; 45 hastaya (\% 54.2) lobektomi, 14 hastaya (\%16.9) pnömonektomi, 11 hastaya (\%13.2) akciğer rezeksiyonu ile birlikte göğüs duvarı rezeksiyonu, 10 hastaya (\%12.1) bilobektomi, 3 hastaya segmentektomi (\%3.6) cerrahisi uygulanmıştı. T3N0M0 subgrubu olarak 38 hasta (\%45.7) çap, 7 hasta (\%8.5) parietal plevra invazyonu, 11 hasta (\%13.2) çevre invazyonu (toraks duvarı, perikard), 10 (\%12.1) hasta satellit nodül ve 17 hasta $(\%$ 20.5) miks olarak T3 sınıfina dahil olmuştu.

Çalışmamızda median sağkalım: 63.3 ay (52.0-74.5 ay), 5 yıllık genel sağkalım $\% 55$ olarak saptandı (resim 1). Cinsiyet ve histopatoloji ile sağkalım arasında istatistiksel olarak anlamlı fark saptanmadı $(\mathrm{p}>0.05)$. Uygulanan cerrahi tipte pnömonektomi grubunda median sağkalım 20.7 ay, diğer cerrahi grupta 70.4 ay olup fark istatistiksel olarak anlaml idi ( $\mathrm{p}=0.005$, HR:3,2, \%95 CI, resim 2). T3 alt gruplarından en iyi median sağkalım çap grubunda 70.1 ay, en kötü sağkalımlar ise invazyon ve miks gruplarda sırasıyla

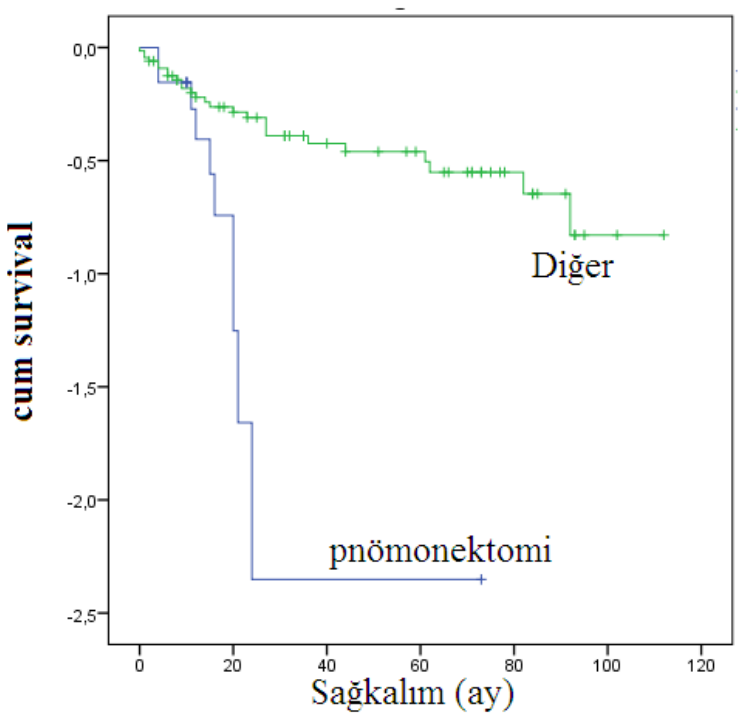

Resim 2: Cerrahi olarak pnömonektomi yapılan grupta sağkalım anlamlı olarak kötü saptandı.

22.0 ve 38.5 ay olup sağkalım farkı istatistiksel olarak anlamlı idi (sirasiyla $\mathrm{p}=0.001$ ve $\mathrm{p}=0.04$, resim 3 ).

\section{TARTIŞMA}

Dünya genelinde kanser ilişkili ölümlerin önde gelen sebebi olan akciğer kanserinde prognozun en önemli belirleyicisi tümörün evresidir. (3). Akciğer kanserinde sağkalımla ilişkili çalışmalar arttıkça kanser evreleri periyodik olarak güncellenmektedir. 2016 da yürürlüğe konulan sekizinci TNM evrelemesinde T3 tümörler heterojen bir grup olup birkaç alt grup içermektedir. Bunlar çap alt grubu ( $>5 \mathrm{~cm}$ ve $\leq 7 \mathrm{~cm}$ ), çevre invazyon

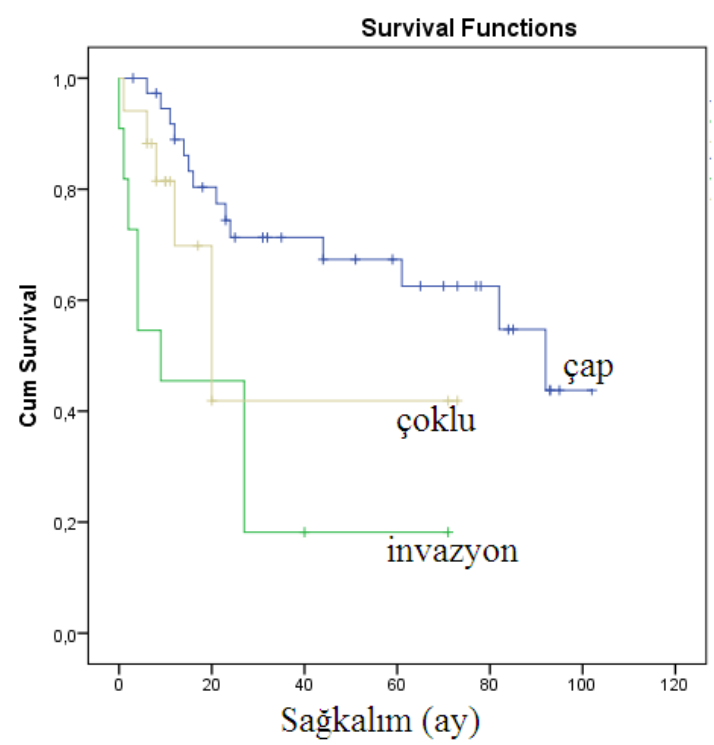

Resim 3: T3N0 evresini oluşturan subgruplar arasındaki karşılaştırmalı sağkalım grafiği. En kötü sağkalım invazyon subgrubunda olup, fark istatistiksel olarak anlamlı idi. 


\section{Sayan et al}

alt grubu (toraks duvarı, parietal perikard ve frenik sinir), satellit nodül alt grubu (aynı lobta 1 den fazla aynı histopatolojideki tümör nodülü) ve parietal plevra invazyon alt grubudur (4). Diğer kanser türlerinde olduğu gibi akciğer kanserlerinde de sağkalım çalışmaları dünya çapında derlenerek benzer sağkalımlı tümör özellikleri aynı evreye alınmaktadır. Çalışmamızda aynı tümör evresinin alt grupları arasındaki sağkalım farkının varlığının araştırılması amaçlandı. Kocaman ve ark. akciğer kanseri ile rezeksiyon uygulanan hastalarda tümör çapının bağımsız bir prognostik faktör olduğunu bildirmiştir (5). Asamura ve ark. evre IIB akciğer kanseri ile ilgili yaptıkları çalışmada tümör çapının lenf nodu invazyonuna göre daha kötü prognozlu olduğunu belirtmişlerdir. (6). Blaauwgeers ve ark T3N0 akciğer kanseri ile ilgili yaptıkları çalışmada en kötü prognozun miks alt grupta olduğunu en iyi prognozun ise satellit nodül grubunda olduğunu saptamışlardır (7). Çalışmamızda invazyon ve miks grubun prognozu çap grubuna göre daha kötü bulunmuştur. Chiappette ve ark gögüs duvarı invazyonuna neden olan akciğer kanseri çalışmalarında median SK: 20.5 ay, 5 yıllık SK: \% 34 olarak bulmuşlardır (8). Gao ve ark. göğüs duvarını invaze eden pT3 akciğer kanserlerinde invazyona ilave olarak tümör çapının $4 \mathrm{~cm}$ den büyük oluşunu kötü prognostik olduğunu ve hastalara adjuvan radyoterapinin gerekli olduğunu bildirmişlerdir. (9). Çalışmamızda nod negatif pT3 hastaların genel sağkalımı 63.3 ay (dağılım:52.0-74.5 ay) iken invazyon grubunda 22.0 ay (dağılım 7.1-37.0) ve miks grupta 38.5 ay (dağılım 18.9-58.1) olarak saptanıp sağkalım fark1 istatistiksel olarak anlamlı idi. Akciğer kanseri cerrahisinde birincil hedef geride makroskopik ve mikroskobik kanser dokusu bırakmayacak şekilde total rezeksiyondur (R0 rezeksiyon). Bununla birlikte literatürde akciğer kanserinde pnömomektomi ameliyatının kendisinin bir hastalık olduğu ve kaçınılması gereken bir prosedür olduğu iddia edilmiştir. (10-12). Çalışmamızda da literatürle uyumlu olacak şekilde cerrahi rezeksiyona göre en kötü sağkalım pnömonektomi grubunda 20.7 ay (dağılım 10.0-31.4 ay) saptandı ve sağkalım farkı istatistiksel olarak anlamlı idi. Literatürde histopatojik alt tiplere göre anlamlı sağkalım farkı elde eden çalışmalar bulmak mümkündür. Cooke ve Alpay tarafindan yapılan çalışmalarda benzer kanser evrelerinde en kötü prognoz adenosquamoz hücreli karsinom alt tipinde elde edilmiştir $(13,14)$. Çalışmamızda histopatolojik gruplar arasında istatistiksel olarak anlamlı fark saptanmasa da en kötü sağkalım skuamoz hücreli karsinom grubunda elde edildi. Çalışmamızın kısıtll1ıkları; tek merkezli ve retrospektif bir çalışma olması, az olgu içermesi ve sadece cerrahi grubu içermesi olarak sayılabilir.

Sonuç: Rezeke edilen akciğer kanserleri ile ilgili sağkalım çalışmaları arttıkça kanser evrelemesinde periyodik değişiklikler yapılmaktadır. Güncel 8. TNM sınıflaması 2016 da kullanılmaya başlamış ve bir sonraki evreleme ile ilgili veriler halen toplanmaktadır. Çalışmamızla aynı tümör evresinde ve aynı T faktöründeki heterojen bir grubu (T3) oluşturan alt gruplar arasındaki sağkalım farkının varlığını araştırmaktı. Çalışmamızda invazyon ve miks alt gruplarda ve cerrahi olarak pnömonektomi yapılan alt grupta sağkalımın anlamlı derecede kötü olduğu sonucuna varıldı. $\mathrm{Bu}$ konudaki çalışmalar arttıkça akciğer kanserinde tümör evrelemesinde yeni kriterler gündeme gelebilecektir.

Çıkar İlişkisi

Tüm yazarlar çıkar çatışması olmadığını beyan eder.

\section{KAYNAKLAR}

1. Blandin Knight S, Crosbie PA, Balata H, Chudziak J, Hussell T, Dive C. Progress and prospects of early detection in lung cancer. Open Biol. 2017; 7. pii: 170070.

2. Feng SH, Yang ST. The new 8th TNM staging system of lung cancer and its potential imaging interpretation pitfalls and limitations with CT image demonstrations. Diagn Interv Radiol. 2019; 25(4): 270-279.

3. Woodard GA, Jones KD, Jablons DM. Lung cancer staging and prognosis. Cancer Treat Res. 2016;170: 47-75.

4. Goldstraw P, Chansky K, Crowley J, Rami-Porta R, Asamura H, Eberhardt WE, et al. The IASLC Lung Cancer Staging Project: proposals for revision of the TNM stage groupings in the forthcoming (eighth) edition of the TNM classification for lung cancer. $J$ Thorac Oncol. 2016; 11(1): 39-51.

5. Kocaman G, Yüksel C, Yenigün BM, Sakallı MA, Karasoy D, et al. Effect of tumor size on survival in pN0M0 non-small cell lung cancer patients A. Curr Thorac Surg. 2016; 1(1): 12-15.

6. Asamura H, Chansky K, Crowley J, Goldstraw P, Rusch VW, Vansteenkiste JF et al. The International Association for the Study of Lung Cancer Lung Cancer Staging Project: proposals for the revision of the N descriptors in the forthcoming 8th edition of the TNM classification for lung cancer. J Thorac Oncol. 2015; 10: 1675-1684.

7. Blaauwgeers H, Damhuis R, Lissenberg-Witte BI, de Langen AJ, Senan S, Thunnissen E. A population-based study of outcomes in surgically resected t3n0 non-small cell lung cancer in the Netherlands, defined using TNM-7 and TNM-8; justification of changes and an argument to incorporate histology in the staging algorithm. J Thorac Oncol. 2019 ;14:459-467.

8. Chiappetta M, Nachira D, Congedo MT, Meacci E, Porziella V, Margaritora S. non-small cell lung cancer with chest wall involvement: integrated treatment or surgery alone? Thorac Cardiovasc Surg. 2019; 67: 299-305.

9. Gao SJ, Corso CD, Blasberg JD, Detterbeck FC, Boffa DJ, Decker RH, et al. Role of adjuvant therapy for node-negative lung cancer invading the chest wall. Clin Lung Cancer. 2017; 18: 169-177. 


\section{Phnx Med J. July, 2020. Volume 2 No 2}

10. Aytekin I, Sanli M, Isik AF, Tuncozgur B, Ulusan A, Bakir K, et al. Outcomes after lobectomy and pneumonectomy in lung cancer patients aged 70 years or older. Turk J Med Sci. 2017; 47: 307-312.

11. Ludwig C, Stoelben E, Olschewski M, Hasse J. Comparison of morbidity, 30-day mortality, and long-term survival after pneumonectomy and sleeve lobectomy for non-small cell lung carcinoma. Ann Thorac Surg. 2005; 79: 968-973.

12. Strand TE, Rostad H, Moller B, Norstein J. Survival after resection for primary lung cancer: a population based study of 3211 resected patients. Thorax. 2006; 61: 710-715.

13. Cooke DT, Nguyen DV, Yang Y, Chen SL, Yu C, Calhoun RF. Survival comparison of adenosquamous, squamous cell, and adenocarcinoma of the lung after lobectomy. Ann Thorac Surg. 2010; 90: 943-948.

14. Alpay L, Evman S, Doğruyol T, Kıral H, Laçin T, Vayvada M, et al. Survival in adenosquamous cancer of the lung: is it really so unfavorable?. Turk Gogus Kalp Dama. 2015; 23: 690-694. 